\title{
A Comparative Study of the Most Influential Learning Styles used in Adaptive Educational Environments
}

\author{
Othmane ZINE ${ }^{1}$, Aziz DEROUICH ${ }^{2}$, Abdennebi TALBI ${ }^{3}$ \\ Higher School of Technology of Fez \\ Sidi Mohamed Ben Abdellah University \\ Fez, Morocco
}

\begin{abstract}
E-learning has evolved from traditional content delivery approaches to a personalized, adaptive and learnercentered knowledge transfer. In the way of customizing the learning experience learning styles represent key features that cannot be neglected. Learning style designates any representative characteristic of an individual while learning, i.e. a particular way of dealing with a given learning task, the preferred media, or the learning strategies adopted in order to achieve a task. Despite the fact that the use of learning styles in adaptive educational environments has become controversial, but there is no empirical evidence of its usefulness. The main objective of our paper is to respond to the question "What learning style model is most appropriate for use in adaptive educational environments?"
\end{abstract}

Keywords-Adaptive educational environments; learning style; Felder-Silverman; personalization; learner modeling

\section{INTRODUCTION}

This template, modified in MS Word 2007 and saved as a "Word 97-2003 Document" for the PC, provides authors with most of the formatting specifications needed for preparing electronic versions of their papers (all standard papers).

Along with the rapid progression of the ICTs for education and the increased efficiency of data acquisition and processing methods, the improvement of the learning quality of e-learning systems became appealing.

As demonstrated in the literature, the learner plays a central role in the complex learning process. And as noticed by teachers, learners aim at different goals, have diverse necessities, distinct backgrounds, skills and other significant characteristics [1]. They vary extremely in the speed and manner with which they collect new information and ideas, and in the confidence with which they process and use them. For example, some studies have highlighted that adult learners learn differently from younger ones ( adult learners and young ones don't learn the same way) [2]. This makes each learner's requirements and preferences unique. The approach to instruction in which a single teaching scenario is used for all learners, better known in the literature as the 'one-size-fits-all' approach, is often unsuitable [3].

Student modeling is the process whereby an adaptive learning system creates and updates a student model by collecting data from several sources implicitly (observing user's behavior) or explicitly (requesting directly from the user). Traditionally, the majority of the student modeling systems has been limited to maintain assumptions related to student's knowledge (acquired during evaluation activities) without paying too much attention to student's preferences.

Learner's individual differences have remarkable potential that should be exploited to provide more accurate guidelines and learning support. This last lead to a better understanding of the subject, to the enhancement of learner's performance and motivation and consequently the optimization of the learning outcomes.

On the one hand, cognitivist and constructivist theories of learning revealed that several learning strategies should be integrated to accommodate individual differences and learning style [4]. On the other hand, researchers claimed that if a learner has a strong preference for a particular learning style, the strategies and even the learning resources should match that style to improve the learning experience [5].

As it is well known, the conventional face to face learning mode grants an accurate recognition of learners' behaviors from their facial expressions, questions and interactions, and so, allows the tutor to choose the right moment and tools to intervene constructively. Thus, it remains imperative to consider these interactions, even if they might be ambiguous in a distance-learning situation.

Traditional e-learning frameworks assume that each learner learns in the same manner through common learning material and instructional design. They are limited in terms of providing personalization and consider a "one fits for all" mindset without considering learner preferences and individual traits. Numerous learners encounter disappointment with such type of frameworks and get exhausted as they progress through their learning cycle since the material is static, and lacks sensitivity to the need of the learner [6]. Plausible remediation is the use of Adaptive Educational Systems (AES) that negate the learning management system the above-mentioned approach and adopt the "one fits one" one.

Learner diversity that exists in the classroom plays a role in influencing the teaching and learning process in the classroom. While all types of learners still need to be addressed, variety in instructional approaches can be used to address this diversity [7]. In addition, the various learning styles as a great deal of ongoing research indicate that learners have different strengths 
and preferences in the way they absorb and process information [8]. Studies in psychology point out that people show noteworthy individual differences in problem-solving and decision-making activities. For instance, students with a solid inclination for a particular learning style may experience problems in learning if the teaching style does not coordinate with their learning style.

Even if researchers still argue on the usefulness of considering students' learning styles in adult education, the use of learning styles measures continues to be popular. And despite the absence of rigorous research findings to support this practice, there is no evidence for its ineffectiveness.

Some researchers claim that learning styles don't match the way the brain stores and reason about information. Others mention that there might be an optimal way to explain a particular subject, but the same style can't always be the best for a specific learner. And rather than focusing on one's best learning style, it is more interesting to on the worst, and try to improve learner's ability to learn in every style.

Even if the idea of learning styles hasn't reached maturity and hasn't proven a total success, there are still many strong reasons which show that employing learning styles can be beneficial to learners. One of the major reasons to use learning styles is because it encourages variety (i.e. as long as a learner feels at ease in the process of learning, no matter what his learning style is, he will learn better). Another reason and as involvement matters, a multimodal classroom is more engaging (i.e. if a learner prefers learning through activities, reading and listening to lectures will make him feel bored and discourage him). Even if learning styles turn out to be nothing more than a personal preference, it is still a creative and smart way to engage learners and enhance their motivation. Moreover, learning styles remind us that each learner is different, and while it is nearly impossible to satisfy all learners, success opportunities can be given to everyone by varying the teaching way at least.

This paper starts by critically examining the most influential learning style models according to the literature and presents a comparative summary of these learning style models (emphasizing their implication on teaching highlighting their strengths and weaknesses). Afterward, it shows how to measure the chosen learning style. Thereafter, it shed light on the impact of learning styles on learners preferred multimedia type. Next, it exposes the instructional design for learning path identification using the Felder-Silverman learning styles model. And finally, it presents a statistical study conducted to identify higher education learners default learning style.

\section{LEARNING STYLE Models ClassifiCATION}

On the one hand, cognitivist and constructivist theories of learning revealed that several learning strategies should be integrated to accommodate individual differences and learning style [4]. On the other hand, researchers claimed that if a learner has a strong preference for a particular learning style, the strategies and even the learning resources should match this style to improve the learning experience [5].

The appellations 'learning style' and 'cognitive style' are commonly used interchangeably, even if cognitive style may denote a specific facet of learning style [4]. Moreover, learning styles are commonly associated with terms as "learning preferences", "learning skills", "learning strategies" and "learning approaches" [9]. This diversity of interpretations and terminologies led to the development of many learning style models.

Given the variety related to learning style, and the existence of a large number of learning models [9], a categorization of these models helps to identify their key features.

The model of Curry's onion can be used to group learning theories into three primary layers according to the degree of stability over time of the preferences represented by each one [10], [11] (see Fig. 1).

- Instructional preference styles (the outer layer of the onion): The least persistent over time, they deal with various modes of information delivery, may often change and therefore are less important in learning.

- Information processing styles (the middle layer): More stable over time than the instructional preference ones, they cope with the information processing way that influences the way learners memorize, infer and interpret information.

- Cognitive personality styles (the inner layer): The most unalterable over time, they are based on personality traits that have a more significative influence on learner's interaction with the learning environment.

Curry's onion model relies on theoretical assumptions and lacks experiential evidence to determine learning style stability [9]. And so, Coffield suggested "The families of learning styles" to classify learning style models with reference to several learning style overviews and on quantitative evidence. This spectrum was inspired from the onion model as well as analyses and overviews by key figures in the learning styles field [12]-[16].

The "families of learning styles" categorizes over seventy learning style models into (see Table I).

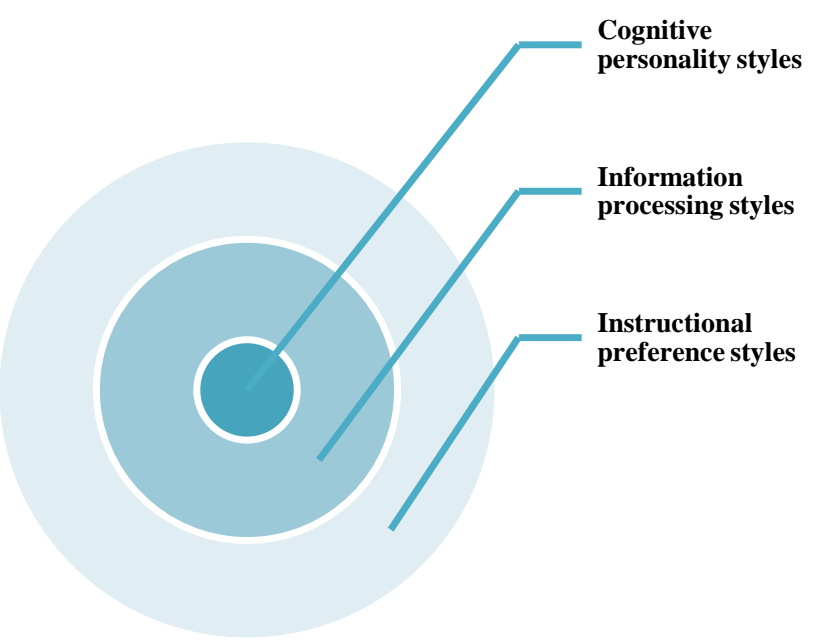

Fig. 1. Curry's Onion Learning Styles Model. 
TABLE. I. COFFIELD'S FAMILIES OF LEARNING STYLES

\begin{tabular}{|l|l|}
\hline $\begin{array}{l}\text { Constitutionally-based } \\
\text { learning styles and } \\
\text { preferences }\end{array}$ & $\begin{array}{l}\text { Dunn and Dunn; Gregorc; Bartlett; Betts; } \\
\text { Gordon; Marks; Paivio; Richardson Sheehan; } \\
\text { Torrance. }\end{array}$ \\
\hline Cognitive structure & $\begin{array}{l}\text { Riding; Broverman; Cooper; Gardner et al.; } \\
\text { Guilford; Holzman and Klein Hudson; Hunt; } \\
\text { Kagan; Kogan; Messick; Pettigrew; Witkin. }\end{array}$ \\
\hline Stable personality types & $\begin{array}{l}\text { Apter; Jackson; Myers-Briggs; Epstein and } \\
\text { Meier; Harrison-Branson; Miller. }\end{array}$ \\
\hline $\begin{array}{l}\text { Flexibly stable learning } \\
\text { preferences }\end{array}$ & $\begin{array}{l}\text { Allinson and Hayes; Herrmann; Honey and } \\
\text { Mumford; Kolb; Felder and Silverman; }\end{array}$ \\
\hline Hermanussen, Wierstra, de Jong and Thijssen; \\
Kaufmann; Kirton; McCarthy.
\end{tabular}

- Constitutionally based learning styles and preferences: Supposed to be fixed and very difficult to change, they are open to relatively easy environmental modification. These styles are mostly innate personality traits and represent the dominance of specific perceptual and sensory channels including the four sensory modalities: visual, auditory, kinesthetic and tactile.

- Cognitive structure: Presumed to be general habits of thought, they reflect intuitive and structural characteristics of the cognitive system and focus on the interactions of cognitive controls and cognitive processes [17].

- Stable personality types: Believed to be mostly stable but can change over time, they are viewed as embedded characteristics within the personality traits which are assumed to shape all aspects of an individual's interaction with the environment.

- Flexibly stable learning preferences: Assumed to have some long-term stability even if they can change slightly from one situation to another, they are viewed as crucial preferences rather than fixed characteristics. This family of learning styles classifies learners in accordance with a measure that mirrors the way they receive and process information.

- Learning approaches and strategies: Frequently changing depending on the situation, they came out from the drop of the learning styles for a holistic and active view of learning approaches and study strategies. They describe how learners prefer to tackle learning tasks generally according to their perceptions of a task and the adopted cognitive strategies [15].

\section{LEARNING STYLE MODELS}

In adaptive e-learning environments, various learning styles theories have been used. In this section, we focused on the most influential learning style models. Since they are the most suitable for the implementation of an adaptive e-learning environment, we are particularly interested in the flexibly- stable learning preferences. However, we decided to take one model from each other family into consideration for reviewing purposes.

\section{A. Gregorc's Mind Styles Model (Constitutionally-based Learning Styles and Preferences Family)}

Anthony Gregorc defines learning styles as stable, cognitive, affective, and physiological traits that serve as indicators of how learners perceive and deal with information and react during learning sessions. Furthermore, he argues the teaching strategies, the personality of individuals, and the media are highly correlated.

He claims that minds interact with any context through channels and that there are two dimensions of learners' innate abilities of perception and ordering, and distinguishes between four observable channels: abstract, concrete, random, and sequential tendencies (see Table II and Fig. 2). A combination of these tendencies is indicative of the individual style. And so, four learning styles are identified within Gregorc's model.

In order to determine learner's learning style, the Style Delineator has been developed, which is a 40 -item self-report inventory involving the rank ordering of sets of words.

\section{B. Riding Cognitive Style (Cognitive Structure Family)}

Riding Cognitive Style model is mainly focused on how cognitive skills develop [16]. Its authors state that the cognitive style is the individual's way of thinking and at the same time the individual's favorite and habitual approaches of organizing and representing information. Furthermore, they define a learning strategy as the processes used by the learner to comply with a learning activity requirement. Besides, they claim that while strategies may be learned and developed over a period of time, styles are static and are relatively innate characteristics of any individual.

The authors claim that their model is oriented essentially to the cognitive skills developing approaches, and so, it influences the study orientation, the instructional inclination, the hands-on learning, the social attitude, and managerial skills.

Riding and Cheema reviewed the descriptions, correlations, methods of assessment, and effect on the behavior of over 30 models, and concluded that they could be grouped into two uncorrelated dimensions: one concerning to cognitive organization (holist-analytic); and one involving mental representation (verbal-imagery) (see Table III and Fig. 3). And Riding states that the first dimension originates from Witkin research on field dependence and field independence [18], while the second is based on the dual coding theory of Paivio [19].

TABLE. II. GREGORC'S Mind STYLES MOdEL

\begin{tabular}{|l|l|l|}
\hline Dimension & Pole & Learning style \\
\hline \multirow{3}{*}{ Perception } & Concrete (C) & \multicolumn{1}{|c|}{ 1. AS } \\
\cline { 2 - 2 } & Abstract (A) & 2. AR \\
Ordering & Sequential (S) & 3. CS \\
\cline { 2 - 2 } & Random (R) & \\
\hline
\end{tabular}




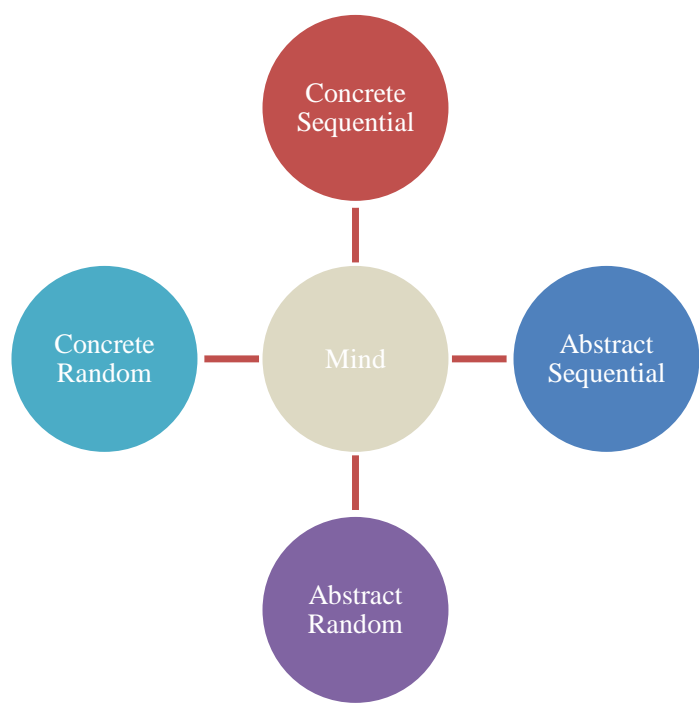

Fig. 2. Gregorc's Four Channels Model.

TABLE. III. RIDING COGNITIVE STYLE

\begin{tabular}{|c|c|c|}
\hline Dimension & Pole & Learning style \\
\hline \multirow{2}{*}{ Cognitive organization } & Holist $(\mathrm{H})$ & \multirow{4}{*}{$\begin{array}{ll}\text { 1. } & \mathrm{HV} \\
\text { 2. } & \mathrm{HI} \\
\text { 3. } & \mathrm{AV} \\
\text { 4. } & \mathrm{AI}\end{array}$} \\
\hline & Analytic (A) & \\
\hline \multirow{2}{*}{ Mental representation } & Verbal (V) & \\
\hline & Imager (I) & \\
\hline
\end{tabular}

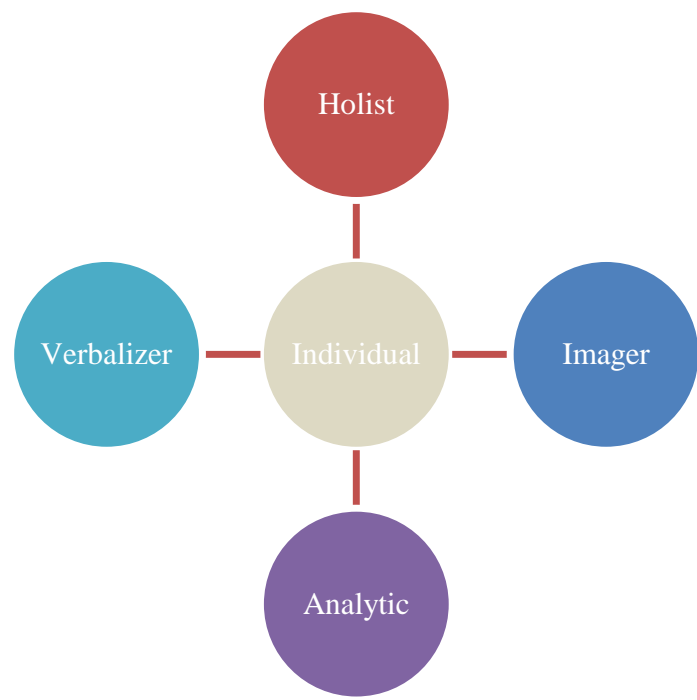

Fig. 3. Riding Cognitive Style uncorrelated Dimensions.

In order to retrieve learner's cognitive style, Riding has developed an assessment method named the Cognitive Styles Analysis (CSA) [20]. The cognitive representation dimension test items are entirely visual and the score is relying on a response speed comparison on a matching task and on embedded figures task analytic preference. And the items for the verbal-imagery dimension are all verbal and are in accordance with the relative speed of categorizing items as being similar through their conceptual similarity or color.

\section{Myer-Briggs Type Indicator Theory (Stable Personality Types Family)}

Developed by Isabel Briggs Myers and her mother, Katharine Cook Briggs, MBTI is a model based on the theory of psychological types of Carl Jung. It aims at helping each person to understand his unique personality. This model is based on the belief that the variances in behavior from one person to another can be expressed in terms of preferences between polarities and each person has a natural preference [21]. Accordingly, when someone uses his favorite pole, he/she generally succeeds better and feels more skilled.

Furthermore, MBTI's dimensions define the four main dichotomies of psychic life and represent humans' personality core functions [22]. Each dimension has two uncorrelated poles, and each person is predisposed to one pole in each dimension (see Table IV). So, this model allows the generating of sixteen unique personality types.

In order to detect learning styles, three forms of the MyersBriggs Type Indicator instrument were developed (a standard 93-item version, an extended 126-item version, and an abbreviated 50-item version). And in all instances, scores are given to generate one of the sixteen unique personality types [23].

\section{Felder-Silverman Learning Style Model (Flexibly Stable \\ Learning Preferences Family)}

The Felder-Silverman learning style model (FSLSM) [5] is, another model based on the work of Carl Gustav Jung, a widely used in adaptive educational systems focusing on learning styles. It describes the learning styles of engineering learners in a detailed way. It distinguishes between preferences on four measurements (dimensions) which are linked to the four dimensions of information (see Table V): information processing (How does the learner prefer to process information), information perception (What type of information does the learner prefer in order to perceive), information input (Through which sensory channel is external information most effectively perceived), and information understanding (How does the learner progress towards understanding) and therefore enables adaptive learning systems to provide a better-tailored learning material [1].

TABLE. IV. MBTI LEARNING STYLE

\begin{tabular}{|c|c|c|}
\hline Dimension & Pole & Learning style \\
\hline \multirow{2}{*}{ Attitude } & Introvert (I) & \multirow{8}{*}{$\begin{array}{ll}\text { 1. } & \text { ISTJ } \\
2 . & \text { ISFJ } \\
3 . & \text { INFJ } \\
4 . & \text { INTJ } \\
5 . & \text { ISTP } \\
6 . & \text { ISFP } \\
7 . & \text { INFP } \\
8 . & \text { INTP } \\
9 . & \text { ESTP } \\
\text { 10. } & \text { ESFP } \\
\text { 11. } & \text { ENFP } \\
\text { 12. } & \text { ENTP } \\
\text { 13. } & \text { ESTJ } \\
\text { 14. } & \text { ESFJ } \\
\text { 15. } & \text { ENFJ } \\
\text { 16. } & \text { ENTJ }\end{array}$} \\
\hline & Extravert (E) & \\
\hline \multirow{2}{*}{$\begin{array}{l}\text { Information } \\
\text { processing }\end{array}$} & Sensing (S) & \\
\hline & iNtuitive (N) & \\
\hline \multirow{2}{*}{$\begin{array}{l}\text { Decisions } \\
\text { making }\end{array}$} & Thinking $(\mathrm{T})$ & \\
\hline & Feeling (F) & \\
\hline \multirow[b]{2}{*}{$\begin{array}{l}\text { Environment } \\
\text { evaluation }\end{array}$} & Judging $(\mathrm{J})$ & \\
\hline & Perceiving $(\mathrm{P})$ & \\
\hline
\end{tabular}


TABLE. V. FELDER-SILVERMAN LEARNING STYLE MODEL

\begin{tabular}{|c|c|c|}
\hline Dimension & Pole & Learning style \\
\hline \multirow{2}{*}{ Perception } & Intuitive (I) & \multirow{8}{*}{$\begin{array}{ll}\text { 1. } & \text { IAVQ } \\
\text { 2. } & \text { IAVG } \\
\text { 3. } & \text { IAEQ } \\
\text { 4. } & \text { IAEG } \\
\text { 5. } & \text { IRVQ } \\
\text { 6. } & \text { IRVG } \\
\text { 7. } & \text { IREQ } \\
\text { 8. } & \text { IREG } \\
\text { 9. } & \text { SAVQ } \\
\text { 10. } & \text { SAVG } \\
\text { 11. } & \text { SAEQ } \\
\text { 12. } & \text { SAEG } \\
\text { 13. } & \text { SRVQ } \\
\text { 14. } & \text { SRVG } \\
\text { 15. } & \text { SREQ } \\
\text { 16. } & \text { SREG }\end{array}$} \\
\hline & Sensing (S) & \\
\hline \multirow{2}{*}{ Processing } & Active (A) & \\
\hline & Reflective (R) & \\
\hline \multirow{2}{*}{ Input } & Visual (V) & \\
\hline & vErbal (E) & \\
\hline \multirow[b]{2}{*}{ Understanding } & seQuential (Q) & \\
\hline & Global (G) & \\
\hline
\end{tabular}

Moreover, FSLSM enables the learning style model to consider exceptional behavior which means that learners with a high preference for a certain behavior can act sometimes differently. This model rates the learner's learning style in a scale of four dimensions to define sixteen distinct learning styles.

In order to detect learning styles, Felder and Soloman elaborated a 44-item questionnaire, named the Index of Learning Styles [24], where 11 questions are asked for each dimension [25].

\section{E. Kolb's Experiential Learning Theory (Flexibly Stable Learning Preferences Family)}

Inspired by the works of John Dewey and Jean Piaget, the American psychologist Kolb developed a four-stages learning style model named "The Experiential Learning Theory" in the early 70s. According to Kolb, the experience is the key element of any learning process, and knowledge comes from the blending of grasping experience and transforming it [26].

He defined a learning model composed of these two orthogonal dimensions (see Table VI). The Grasping dimension poles are Concrete Experience (when the learner is confronted to a new situation or a remake of similar previous experience) and Abstract Conceptualization (when the learner's reflections initiate a new understanding or the expansion of the current knowledge). Likewise, the Transforming poles are Reflective Observation (when the learner observes the new experience and positions in accordance with his/her prior knowledge) and Active Experimentation (when the learner puts his or her newly acquired or expanded knowledge into practice).

Kolb proposed a four-stage hypothetical learning cycle and claimed that these four stages are interrelated, with each one leading to the following. He assumed that we can enter the learning cycle at any stage and learners will show a preference for some phases more than others. A learner can start with direct experience and makes it specific or of an abstract experience $(\mathrm{AC} / \mathrm{CE})$. Then these experiences (concrete or abstract) are transformed into knowledge when we reflect and think about them or when we experiment an active form of the received information ( $\mathrm{RO} / \mathrm{AE})$.
For instance, student A goes through a concrete situation and accumulates experience (CE), this leads him to make some observations and reflections about the situation (RO), later on he will build abstract concepts and theories to explain these observations (AC), which he can actively experiment and validate to make decisions or resolve problems (AE). Once the circle is complete the learning outcome leads to the construction of new experiences which triggers the cycle of learning all over again (see Fig. 4).

In order to assess an individual's preferred modes of learning, Kolb elaborated a forced-choice ranking questionnaire that the subject has to complete, named the Kolb's Learning Style Inventory. It evaluates the individual's abilities throughout two spectrums: concrete experience to abstract conceptualization, and active experimentation to reflective observation. The first version of the LSI appeared in 1976, and it was revised several times $(1985,1999$, and 2011) [27].

\section{F. Honey and Mumford's Model (Flexibly Stable Learning Preferences Family)}

Grounded in Kolb's theory, Honey and Mumford learning style model describes learning styles as behaviors and attitudes that determine individual learning preferences [28], [29]. They claim that people learn in the same way as experimental scientists conduct research and that learners' learning styles differ according to the phases of the learning process which they are best at. Despite the fact that their theory also relies on the steps of the experiment process, it doesn't assume the establishment of bipolar dimensions, as is the case with Kolb.

TABLE. VI. KOLB LEARNING STYLE MODEL

\begin{tabular}{|c|c|c|}
\hline Dimension & Pole & Learning style \\
\hline \multirow{2}{*}{$\begin{array}{l}\text { Grasping / } \\
\text { Prehension }\end{array}$} & Concrete Experience (CE) & \multirow{4}{*}{$\begin{array}{ll}\text { 1. } & \text { Diverging } \\
\text { 2. } & \text { (CE/RO) } \\
\text { 3. } & \text { Assimilating } \\
\text { 4. } & \text { (AC/RO) } \\
\text { 5. } & \text { Converging } \\
\text { 6. } & \text { (AC/AE) } \\
\text { 7. } & \text { Accommodating } \\
\text { 8. } & \text { (AC/AE) }\end{array}$} \\
\hline & $\begin{array}{l}\text { Abstract Conceptualization } \\
\text { (AC) }\end{array}$ & \\
\hline \multirow{2}{*}{$\begin{array}{l}\text { Transforming } \\
\text { / Processing }\end{array}$} & Reflective Observation (RO) & \\
\hline & Active Experimentation (AE) & \\
\hline
\end{tabular}

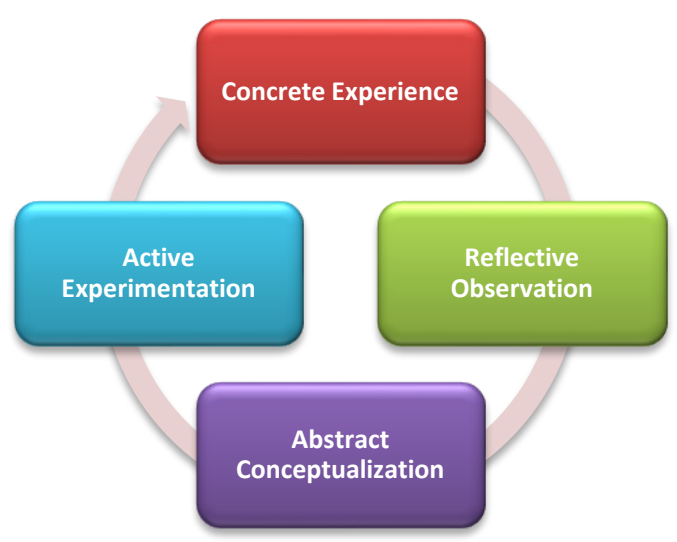

Fig. 4. The Experimental Learning Theory Learning Cycle 


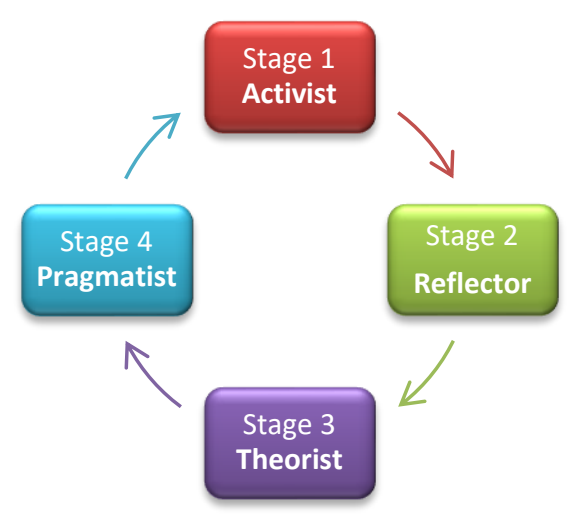

Fig. 5. H and M Learning Style Model.

The authors refer to the learning styles with the four stages (see Fig. 5): Activists (i.e. individuals who approve experiencing); Reflectors (i.e. individuals who rather reviewing experiences or pondering over facts); Theorists (i.e. individuals who favor reasoning); and pragmatists (i.e. individuals who prefer planning the next steps).

Honey and Mumford's intention is that learners should become proficient in all four stages of the learning cycle.

In order to assess an individual's learning style, Honey and Mumford Learning Style Questionnaire was developed. It consists of 80 items with true/false answers that probe preferences for four learning styles, with 20 items for each style.

\section{G. Entwistle's Approaches to Learning and Studying Inventory (Learning Approaches and Strategies Family)}

Noel Entwistle, a researcher in the field of educational psychology, and his colleagues developed a "teaching-learning process" experimental model in order to guide institutions to undertake a process of critical reflection on their adopted methods with the intention of reforming the whole learning environment to enhance the student learning quality ( $\mathrm{N}$. Entwistle 1990). This model intends to encompass the problematic influence structure that links motivation, academic performance and learning approaches with the indirect effects of teaching and assessment methods. Furthermore, it aims to identify the students' tendencies to adopt deep, surface and strategic approaches to learning and studying.

Entwistle defined a strategy as the manner a learner chooses to confront a specific learning assignment in accordance with its observed requirements and a style as an extensive description of a learner's favored approach of dealing with learning tasks generally [30]. Moreover, he distinguishes three separate learners' personality types in higher education courses in conformity with studies on the effects of personality on learning: non-committers, hustlers and plungers. While the first category of learners tends to be thoughtful, anxious and risk-averse, the second one is composed of competitive, dynamic but insensitive students, and the third gathers sensitive, thoughtless and self-reliant ones.

The Approaches to Learning and Studying Inventory (ALSI) have been developed to evaluate learners' approaches to learning and their perceptions about the course organization and the teaching impact (N. J. Entwistle, McCune, and Tait 1997). It was derived from evaluations of other measures, namely, the Approaches to Studying Inventory (ASI-1981); the Course Perception Questionnaire (CPQ-1981); the Revised Approaches to Studying Inventory (RASI-1995) (N. Entwistle and McCune 2004); and the Approaches and Study Skills Inventory for Students (ASSIST-1997).

The complete version of the ALSI questionnaire uses a Likert technique to determine students' attitudes by rating a series of related items that deal with the aspects of a specific construct (deep, surface and strategic) on a five-point scale. It incorporates three parts: The first one is concerned with students' perceptions of learning. The second relates to their study practices; The third involves students' preferences for different kinds of teaching (N. Entwistle and Tait 2013).

\section{DISCUSSION}

This section defines the comparative summary of the selected most influential learning style models. The following table (see Table VII) summarizes this discussion and shows the learning style's model name, family, instrument, strengths, and weaknesses.

The Gregorc's Mind Styles Model relies on individuals' instinctive abilities of 'perception' and 'ordering'. While Gregorc states that his model has high levels of internal consistency and test-retest reliability, no evidence for his theoretical claim is provided and significant uncertainties were expressed about its psychometric properties in the literature. Concerning validity, moderate correlations are reported for criterion-related validity, but there is no empirical evidence for construct validity. Some of the words used in the instrument are unclear or may be unfamiliar to the end-users which makes it irrelevant for the assessment of individuals.

Even if the Riding Cognitive Style Model is known for its simplicity, it lacks empirical evidence and suffers from unresolved conceptual problems and serious difficulties with its instrument. Within this model, only cognitive aspects of thinking and learning are dealt with without taking into account the affective and conative ones. Moreover, learning styles are assumed to be fixed, and metacognitive training which might lead to learning styles alteration is not considered. The author hasn't provided any evidence about its reliability, while other studies have revealed that internal consistency and test-retest reliability are very poor. And finally, its pedagogical impact is questionable.

The Myer-Briggs Type Indicator Model was specifically designed as a tool to classify an individual's personality type in general, and their approaches to relationships with others. Some researchers in the learning styles field choose to exclude the MBTI on the grounds that its scope as a personality measure outweighs cognitive regulations and behavior specifically related to learning. Furthermore, victim of its own massive commercial success of the MBTI as style measurement instrument, some of the critical and experiential examinations done with it are superficial and neglectful. That's why the research evidence to advocate it as an effective style evaluation and pedagogical support is still unconvincing. On the one hand, there has been considerable debate about the 
construct validity of the MBTI and the irrelevant forced-choice format of the instrument. On the other hand, the stability of the MBTI types allocations is open to question in part because the middle scores are prone to misinterpretation due to small numerical differences. Finally, the practical application of MBTI in pedagogy is still ambiguous as there is no evident perception of how type dynamics impact on education.

The Felder-Silverman Learning Styles Model beneficiates from a considerable amount of available literature and has been frequently used by educators in different disciplines for providing adaptivity regarding learning styles in e-learning environments as it provides a detailed description of the different dimensions of the learner's style and taking into account inclinations on four measurements. Moreover, its instrument, the ILS, has undergone multiple studies according to the literature and has proved to be user-friendly and effective for instruction and assessment design in accordance with the learners' learning styles because the results are easy to interpret, and because the number of dimensions is controlled and can, in fact, be implemented. Even if there is no full consensus on studies results, they have shown satisfactory convergent and discriminant validity, scarce reliability, and satisfactory consistency.

The Kolb's Experiential Learning Theory is one of the first learning style models, based on an explicit theory, that engaged a tremendous international literature dedicated to its examination. However, Kolb disrecommends the use of its instrument, the LSI, for individual selection purposes as it cannot measure individuals with thorough precision. Moreover, the psychometric properties of the LSI have been the subject of criticism, and there is no unequivocal evidence in the literature that shows that it enhances academic performance. Although the LSI beneficiated from the critique to improve the reliability of the instrument, the test-retest reliability suggests that the LSI is rather volatile and the reliability coefficients for the four basic scales are not (enough) satisfactory.

While Honey and Mumford's Model can be used for personal development by drawing proposals to help individuals to fortify underexploited styles, studies prove it uselessness for individuals' selection on the basis of their learning styles as it exposes no enough distinctive scale scores to allow them to be categorized. Moreover, it labels individuals while most people show more than one strong style. And even if it has been extensively used in the professional field, it requires to be reformed to transcend shortcomings critics showed when evaluated by researchers and more proofs of its validity are essential in order to adopt it with confidence.

Entwistle' Approaches to Learning and Studying Inventory is an important aid for the discussion and diagnosis of the effective and ineffective strategies for learning in accordance with learners' actual approaches as a basis for redesigning instruction and assessment. However, the use of the instrument for adapting the pedagogic environment turned out to be difficult for non-specialists who lack an in-depth understanding of its underlying implications. The model has undergone extensive evaluation and the result showed satisfactory reliability and internal consistency but contested construct and predictive validity. Moreover, the external analysis confirmed the validity of the deep, surface and strategic approaches. All in all, this model needs to be redesigned, tested and revalidated for pedagogical interventions.

All the aforementioned things considered; the FelderSilverman Learning style model reveals itself to be the most appropriate model for providing adaptivity and accurate instruction and assessment design in accordance with the learners' learning styles in e-learning environments.

Moreover, and according to the literature, Felder Silverman model turned out to be the most preferred model of learner style used in the learning theories and has been successfully implemented in many previous works when individually adapting the learning material. Author in [31] within the scope of adaptive education systems, inspected 69 studied published from 2005 to 2014. The results revealed that the FelderSilverman learning style model was the most preferred model (42\%), followed by the Kolb model $(14.5 \%)$. In another work, [32] examined integrating learning styles in adaptive e-learning systems by reviewing 51 studies published from (2004 to 2014). The results of this study show that the Felder-Silverman learning style model was the most preferred model $(70.6 \%)$, and then the VARK model (9.8\%). In a more recent study, [6] investigated the researches on learning styles used in e-learning environments published between the years 2001 to 2016. y When these studies were classified by considering the used learning style, it has been observed that Felder Silverman model was the most preferred model of learner style used in the learning theories $(n=33 ; 46.67 \%)$, followed by Kolb model $(n=14 ; 19.71)$. 
TABLE. VII. LEARNING STYLES ModELS' COMPARISON

\begin{tabular}{|c|c|c|c|c|c|}
\hline Model & Family & Instrument & $\begin{array}{l}\text { Instrument } \\
\text { mechanism }\end{array}$ & Strengths & Weaknesses \\
\hline Gregorc & $\begin{array}{l}\text { Constitutionally } \\
\text { based learning } \\
\text { styles and } \\
\text { preferences }\end{array}$ & $\begin{array}{l}\text { Gregorc Style Delineator } \\
\text { (GSD) }\end{array}$ & $\begin{array}{l}\text { Rank a set of } \\
\text { items }\end{array}$ & $\begin{array}{ll}\checkmark & \text { Considerable internal } \\
& \text { consistency } \\
\checkmark & \text { High test-retest reliability } \\
\checkmark & \text { Moderate criterion-related } \\
& \text { validity }\end{array}$ & $\begin{array}{cl}\times & \text { Poor psychometric properties. } \\
\times & \text { Static learning styles } \\
\times & \text { Undemonstrated construct validity } \\
\times & \text { Theoretical evidence of the } \\
& \text { pedagogical impact } \\
\times & \text { Irrelevant for the individuals } \\
& \text { assessment } \\
\end{array}$ \\
\hline Riding & $\begin{array}{l}\text { Cognitive } \\
\text { structure }\end{array}$ & $\begin{array}{l}\text { Cognitive Styles Analysis } \\
\text { (CSA) } \\
\text { (1991) }\end{array}$ & $\begin{array}{l}\text { Select only one } \\
\text { answer from two } \\
\text { alternatives }\end{array}$ & $\begin{array}{ll}\checkmark & \text { Simplicity } \\
\checkmark & \text { Acceptable face validity }\end{array}$ & $\begin{array}{ll}\times & \text { Debatable conceptual issues } \\
\times & \text { Weak internal consistency } \\
\times & \text { Very low test-retest reliability } \\
\times & \text { Questionable evidence of pedagogical } \\
& \text { impact } \\
\times & \text { Unreliable instrument } \\
\end{array}$ \\
\hline MBTI & $\begin{array}{l}\text { Stable } \\
\text { personality types }\end{array}$ & $\begin{array}{l}\text { Myers- Briggs Types } \\
\text { Indicator (MBTI) } \\
(\mathbf{1 9 6 2 )}\end{array}$ & $\begin{array}{l}\text { Likert scale } \\
\text { question }\end{array}$ & $\begin{array}{ll}\checkmark & \text { Provides a view of the whole } \\
& \text { personality } \\
\checkmark & \text { High-reliability coefficients } \\
\checkmark & \text { Approved face validity }\end{array}$ & $\begin{array}{ll}\times & \text { Not learning specific } \\
\times & \text { Complicated relationships between } \\
& \text { elements and scales } \\
\times & \text { Weak stability of the learning styles } \\
\times & \text { Contestable construct validity } \\
\times & \text { No proof of any beneficial outcomes } \\
& \text { concerning the pedagogical impact }\end{array}$ \\
\hline FSLSM & $\begin{array}{l}\text { Flexibly stable } \\
\text { learning } \\
\text { preferences }\end{array}$ & $\begin{array}{l}\text { Index of Learning Styles } \\
\text { (ILS) } \\
\text { (1996) }\end{array}$ & $\begin{array}{l}\text { Select only one } \\
\text { answer from two } \\
\text { alternatives }\end{array}$ & $\begin{array}{ll}\checkmark & \text { Learning specific } \\
\checkmark & \text { Flexible and stable learning } \\
& \text { styles } \\
\checkmark & \text { Detailed description of the } \\
& \text { learning style of a learner } \\
\checkmark & \text { Widespread use } \\
\checkmark & \text { Satisfactory convergent and } \\
\checkmark & \text { discriminant validity } \\
\checkmark & \text { Scarce reliability } \\
\checkmark & \text { Convenient for instruction } \\
& \text { individualization }\end{array}$ & Low predictive validity \\
\hline Kolb & $\begin{array}{l}\text { Flexibly stable } \\
\text { learning } \\
\text { preferences }\end{array}$ & $\begin{array}{l}\text { Learning Style Inventory } \\
\text { (LSI) } \\
(\mathbf{1 9 7 6 )} \\
\text { Revised Inventory } \\
\text { (R-LSI) } \\
\text { (1985) } \\
\text { Learning Style Inventory- } \\
\text { v3 } \\
(1999)\end{array}$ & $\begin{array}{l}\text { Rank a set of } \\
\text { items }\end{array}$ & $\begin{array}{ll}\checkmark & \text { Flexible and stable learning } \\
& \text { styles } \\
\checkmark & \text { Reliable instrument } \\
\checkmark & \text { Convenient for instruction } \\
& \text { individualization }\end{array}$ & $\begin{array}{ll}\times & \text { Unsuitable for individual selection } \\
\times & \text { Deficient notion of a learning cycle } \\
\times & \text { Doubtful psychometric properties } \\
\times & \text { Controversial reliability } \\
\times & \text { Disputed construct validity } \\
\times & \text { Low predictive validity } \\
\times & \text { Theoretically-based the pedagogical } \\
& \text { impact }\end{array}$ \\
\hline$H \& M$ & $\begin{array}{l}\text { Flexibly stable } \\
\text { learning } \\
\text { preferences }\end{array}$ & $\begin{array}{l}\text { LS Questionnaire (LSQ) } \\
\text { (1982) }\end{array}$ & $\begin{array}{l}\text { Mark a set of } \\
\text { items }\end{array}$ & $\begin{array}{ll}\checkmark & \text { Learning specific } \\
\checkmark & \text { Helpful for individuals to } \\
& \text { fortify an under-used style } \\
\checkmark & \text { Instrument translated into } \\
\text { dozens of languages }\end{array}$ & $\begin{array}{ll}\times & \text { Individuals labeling } \\
\times & \text { Useless for assessment/selection } \\
\times & \text { Very criticized model design } \\
\times & \text { Moderate internal consistency } \\
\times & \text { Speculative validity } \\
\times & \text { No empirical evidence of pedagogical } \\
& \text { impact }\end{array}$ \\
\hline Entwistle & $\begin{array}{l}\text { Learning } \\
\text { approaches and } \\
\text { strategies }\end{array}$ & $\begin{array}{l}\text { Approaches to Studying } \\
\text { Inventory (1981) } \\
\text { Course Perception } \\
\text { Questionnaire } \\
\text { (1981) } \\
\text { Revised Approaches to } \\
\text { Studying Inventory } \\
\text { (1995) } \\
\text { Approaches and Study } \\
\text { Skills Inventory for } \\
\text { Students } \\
\text { (1997) } \\
\text { Approaches to Learning } \\
\text { and Studying Inventory } \\
\text { (2007) }\end{array}$ & $\begin{array}{l}\text { Rank a set of } \\
\text { items }\end{array}$ & $\begin{array}{ll}\checkmark & \text { Learning orientations } \\
\checkmark & \text { assessment } \\
& \text { Course organization and } \\
& \text { instruction preferences } \\
& \text { evaluation } \\
\checkmark & \text { Satisfactory reliability and } \\
& \text { internal consistency } \\
\checkmark & \text { Confirmed validity of deep, } \\
& \text { surface and strategic } \\
\checkmark & \text { approaches } \\
& \text { A basis for discussing the } \\
\text { effective and ineffective } & \text { strategies for learning } \\
\checkmark & \text { A basis for redesigning } \\
\text { instruction and assessment }\end{array}$ & $\begin{array}{ll}\times & \text { Complex model } \\
\times & \text { Instrument with limited accessibility } \\
\times & \text { Requires in-depth understanding } \\
\times & \text { Test-retest reliability is not } \\
& \text { demonstrated. } \\
\times & \text { Contested construct and predictive } \\
& \text { validity } \\
\times & \begin{array}{l}\text { Difficulties to transform the learning } \\
\text { environment in accordance with the }\end{array} \\
& \text { instrument results } \\
\times & \begin{array}{l}\text { No empirical evidence for the } \\
\text { pedagogical impact }\end{array}\end{array}$ \\
\hline
\end{tabular}




\section{CONCLUSION}

Through the review of learning style research, we found several models and assessment instruments that can be applied to university's education. Many of these have been adapted as online tests. The review shows that the Felder Silverman model is the most suitable for adaptive e-learning for the aforementioned and discussed reasons.

Future research and empirical studies will be done specifically to investigate the efficiency of these learning styles for optimal learning and teaching experience that leads to better learning outcomes. Moreover, all of the existing learning style instruments were built using only the textual form of information, which is considered more suitable for verbal learners than others. Consequently, and in order to increase the efficiency of the ILS instrument, we are thinking of constructing another form of the standard questionnaire that will be more convenient for a larger panel of users using the different forms of information. Furthermore, a future paper will be dedicated to how can we ideally detect learners' learning style in a hybrid manner by combining the use of the revised form of the questionnaire to initialize the model and automatic detection techniques to update it after each learning session.

\section{REFERENCES}

[1] S. Graf, T. C. Liu, Kinshuk, N. S. Chen, and S. J. H. Yang, "Learning styles and cognitive traits - Their relationship and its benefits in webbased educational systems," Comput. Human Behav., vol. 25, no. 6, pp. 1280-1289, 2009.

[2] L. J. Ausburn, "The freedom versus focus dilemma in a customized selfdirected learning environment: A comparison of the perceptions of adult and younger students," Community Coll. J. Res. Pract., vol. 26, no. 3, pp. 225-235, 2002.

[3] M. Šimko, M. Barla, and M. Bieliková, "ALEF: A framework for adaptive web-based learning 2.0," in IFIP International Conference on Key Competencies in the Knowledge Society, 2010, pp. 367-378.

[4] S. Cassidy, "Learning Styles: An overview of theories, models, and measures," Educ. Psychol., vol. 24, no. 4, pp. 419-444, Aug. 2004.

[5] R. M. Felder and L. K. Silverman, "Learning and teaching styles in engineering education," Eng. Educ., 1988.

[6] N. Kumar, Amit; Ahuja, Neelu Jyothi; Singh, "Learner characteristics based learning style models classification and its implications on teaching," Int. J. Pure Appl. Math., vol. 118, no. 20, pp. 175-184, 2018.

[7] L. Mei Ph'ng, "Teaching Styles, Learning Styles and the ESP Classroom," MATEC Web Conf., vol. 150, p. 05082, Feb. 2018.

[8] W. B. James and D. L. Gardner, "Learning styles: Implications for distance learning," New Dir. Adult Contin. Educ., vol. 1995, no. 67, pp. 19-31, 1995.

[9] F. Coffield, D. Moseley, E. Hall, and K. Ecclestone, Learning styles and pedagogy in post-16 learning A systematic and critical review. 2004.

[10] L. Curry, "An organization of learning styles theory and constructs.," Educ. Res. Inf. Cent., pp. 2-28, 1983.

[11] L. Curry, "Review of learning style, studying approach, and instructional preference research in medical education," Int. Perspect. Individ. Differ., vol. 1, pp. 239-276, 2000.
[12] M. A. Bokoros, M. B. Goldstein, and M. M. Sweeney, "Common factors in five measures of cognitive style," Curr. Psychol., vol. 11, no. 2, pp. 99-109, 1992.

[13] J. Chevrier, G. Fortin, M. Théberge, and R. Le Blanc, "Le style d'apprentissage: une perspective historique," Le style d'apprentissage, vol. 28 , no. $1,2000$.

[14] L. Curry, "Patterns of Learning Style Across Selected Medical Specialties," Educ. Psychol., vol. 11, no. 3-4, pp. 247-277, 1991.

[15] N. Entwistle, V. McCune, and P. Walker, "Conceptions, styles, and approaches within higher education: Analytic abstractions and everyday experience," Perspect. thinking, Learn. Cogn. styles, pp. 103-136, 2001.

[16] R. Riding and I. Cheema, "Cognitive styles-an overview and integration," Educ. Psychol., vol. 11, no. 3-4, pp. 193-215, 1991.

[17] R. Riding and S. Rayner, Cognitive styles and learning strategies: Understanding style differences in learning and behavior. David Fulton Publishers, 2013.

[18] H. A. Witkin, R. B. Dyk, H. F. Fattuson, D. R. Goodenough, and S. A. Karp, "Psychological differentiation: Studies of development.," 1962.

[19] A. Paivio, Imagery and verbal processes. Psychology Press, 2013.

[20] E. Sadler-Smith and R. Riding, "Cognitive style and instructional preferences,” Instr. Sci., vol. 27, no. 5, pp. 355-371, 1999.

[21] I. B. Myers, M. H. McCaulley, and R. Most, Manual, a guide to the development and use of the Myers-Briggs type indicator. consulting psychologists press, 1985.

[22] S. A. Girelli and J. E. Stake, "Bipolarity in Jungian Type Theory and the Myers--Briggs Type Indicator,” J. Pers. Assess., vol. 60, no. 2, pp. 290 301, 1993.

[23] R. M. Capraro and M. M. Capraro, "Myers-briggs type indicator score reliability across: Studies a meta-analytic reliability generalization study," Educ. Psychol. Meas., vol. 62, no. 4, pp. 590-602, 2002.

[24] B. A Soloman and R. Felder, "Index of Learning Styles Questionnaire," 1999. [Online]. Available: https://www.webtools.ncsu.edu/learning styles/. [Accessed: 10-May-2019].

[25] S. El Lakkah, M. A. Alimam, and H. Seghiouer, "Adaptive e-learning system based on learning style and ant colony optimization," in 2017 Intelligent Systems and Computer Vision (ISCV), 2017, pp. 1-5.

[26] A. Y. Kolb and D. A. Kolb, "Learning Styles and Learning Spaces: Enhancing Experiential Learning in Higher Education," Acad. Manag. Learn. Educ., vol. 4, no. 2, pp. 193-212, Jun. 2005.

[27] Kolb and D. a Kolb, "The Kolb Learning Style Inventory 4.0," Exp. Based Learn. Syst. Inc., no. January 2005, pp. 1-72, 2013.

[28] K. Knight, "Book Reviews : The Manual of Learning Styles Peter Honey and Alan Mumford," Manag. Educ. Dev., vol. 14, no. 2, pp. 147-150, Jul. 1983.

[29] P. Honey and A. Mumford, The learning styles helper's guide. Peter Honey Publications Maidenhead, 2000.

[30] N. Entwistle, M. Hanley, and D. Hounsell, "Identifying distinctive approaches to studying," High. Educ., vol. 8, no. 4, pp. 365-380, 1979.

[31] Ö. Özyurt and H. Özyurt, "Learning style based individualized adaptive e-learning environments: Content analysis of the articles published from 2005 to 2014," Comput. Human Behav., vol. 52, pp. 349-358, Nov. 2015.

[32] H. M. Truong, "Integrating learning styles and adaptive e-learning system: Current developments, problems and opportunities," Comput. Human Behav., vol. 55, pp. 1185-1193, 2016. 